Environment Conservation Journal 15(3)143-148, 2014

ISSN 0972-3099 (Print) 2278-5124 (Online)

Abstracted and Indexed

\title{
A study of physico-chemical properties of ground water of Kheralu taluka, Gujarat, India
}

\author{
Punita Parikh $^{1}$ and Rahul Parikh ${ }^{2}$ \\ Received: 07.03.2014 \\ Revised:11.10.2014 \\ Accepted:02.11.2014
}

\begin{abstract}
The Mehsana district located in North Gujarat has experienced a growing concern because of itsrecent association with Fluoride toxicity in the form of endemic dental and skeletal fluorosis. The extensive agricultural consumption of groundwater in the area has led to the depletion of its quality. Therefore the present study was aimed to evaluate the groundwater quality, by checking its suitability for drinking water purpose and finding out major contaminants in the area. To fulfill the pupose of study water samples from 60 villages were collected and analysed for various physicochemical parameters including major cations and anions and were statistically analysed. Geochemical evaluation was also performed using Pipers diagram. 53\% samples were moderately hard, $\mathbf{3 0 \%}$ samples were exceeding permissible limit of alkalinity while $\mathbf{4 5 \%}$ samples have high fluoride content. The hydro-geochemical faces shows that water of kheralutaluka is dominated by alkaline earth metals $\left(\mathrm{Ca}^{2+}\right.$ and $\left.\mathrm{Mg}^{2+}\right)$ and the major types of water are of $\mathrm{Ca}-\mathrm{Cl}-\mathrm{HCO3}, \mathrm{Ca}-\mathrm{HCO3}-\mathrm{Cl}$ and $\mathrm{Na}-\mathrm{HCO3}-\mathrm{Cl}$ rest all other samples have mix faces.
\end{abstract}

Keywords: Drinking water quality, Groundwater, Kheralu taluka

\section{Introduction}

Availability of fresh water is the major question for todays world. Humans rely on groundwater not only as a source of drinking water but also for various agricultural, industrial and recreational uses. Groundwater constitutes $97 \%$ of total global freshwater and in many regions constitutes the single largest available supply of fresh drinking water (WHO, 2004). With the advent of rapid urbanization, industrialization and modern agriculture, there is pressure on groundwater in terms of both quality and availability. Hence, it is very important to assess the groundwater quality not only for its present use but also from the viewpoint of a potential source of water for future consumption (Kori et al., 2006). Variation of groundwater quality in an area is a function of physical and chemical parameters that are greatly influenced by geological formations and anthropogenic activities.The Mehsana district, Gujarat, India, has experienced a growing concern because of its recent association with Fluoride toxicity in the form of endemic dental and skeletal fluorosis. Earlier studies carried out in this area (Patel and Bhatt, 2007) have evaluated Fluoride concentration in groundwater with few other

\section{Author's Address}

Department of Botany,

The M. S. University of Baroda, Vadodara

E-mail: punitaparikh@gmail.com potable parameters. Chinoy et al. (1994) worked on fluoride impacts on human beings. Gupta et al., (2005) addressed the hydrogeological aspects of fluoride in water. These studies, however, have not attempted to assess the seasonal variation of groundwater quality in the rural areas of Mehsana district, Gujarat. Therefore the present work aimed at evaluating seasonal variation in groundwater quality with special attention on Fluoride in the villages of Kheralutaluka of Mehsana district during the year 2012-13.

\section{Material and Methods}

\section{Profile of the study site}

The study area i.e Kheralu Taluka is located at the north-eastern part of the Mehsana District in Gujarat state (Fig. 1). It is located between $23.82^{\circ} \mathrm{N}$ to $23.98^{\circ} \mathrm{N}$ latitude and $72.48^{\circ} \mathrm{E}$ to $72.79^{\circ} \mathrm{E}$ longitude covering an area of $334.24 \mathrm{~km}$. The climatic condition of the study area is semi arid with temperature varying from $42^{\circ} \mathrm{C}$ to $20^{\circ} \mathrm{C}$. Rainfall is scanty about $350 \mathrm{~mm}$. Soil is alluvial sandy type.

\section{Sample collection}

A total of 60 samples of groundwater used for drinking purpose were collected from drinking and 


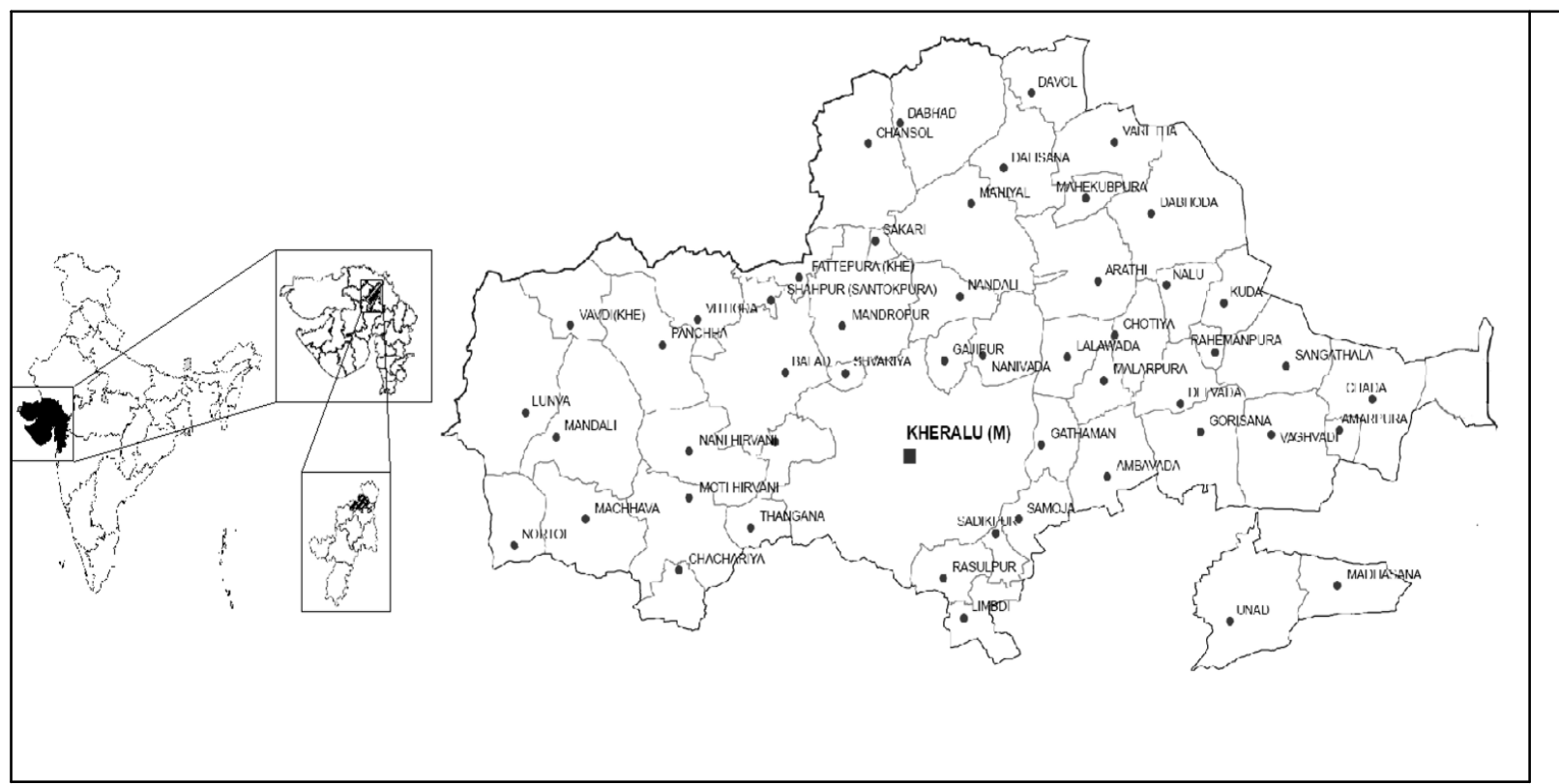

Figure 1: Kheralu map

irrigation wells (open, dug wells and hand pumps) from different villages which spread over the 46 panchayats of the block before sampling, the water left to run from the source for few minutes. Then water samples collected in pre-cleaned, sterilized polyethylene bottles of $1 \mathrm{~L}$ capacity. The samples were immediately dispatched to the laboratory for physico-chemical analyses.

\section{Analysis of Groundwater Samples}

The fluoride concentration in the collected ground water samples was estimated using ion selective electrode (model 290 A+, "Orion Research make"). The other potable parameters like temperature , electrical conductivity, $\mathrm{pH}$, turbidity, TS, TSS, TDS, potassium, sodium, acidity, alkalinity, chloride and hardness were analysed using standard methods (APHA- AWWA, 1998).

\section{Results and Discussion}

It was noted by direct observation that all the water samples were colourless and odourless. $\mathrm{pH}$ is considered as an important ecological factor and provides an important piece of information in many type of geochemical equilibrium or solubility calculation $\mathrm{pH}$ values of water samples were in the range of 7.2 (Dalisana) - 8.6 (NaniHirvani) (Table 1). All the samples were in prescribed limit of BIS (1991) except Nanihirvani (8.6).
The result revealed alkaline nature of the groundwater of all the tested samples. This is because fluoride bearing water is generally high in alkalinity. In mineralogical study of this area, we found that fluoroapatide and biotite micas contain fluoride ion. It may be because that apatite may perhaps exchange some of its hydroxyl ion for fluoride. Alkaline $\mathrm{pH}$ favours the solubility of fluoride bearing minerals. In acidic medium (acidic $\mathrm{pH}$ ), fluoride is adsorbed in clay; however, in alkaline medium it is desorbed, and thus alkaline $\mathrm{pH}$ is more favorable for fluoride dissolution activity. Similar study was conducted in Dhampur, Bijnor district of Uttar Pradesh by who also reported high alkaline nature of groundwater samples. Alkalinity values of the samples varied from $125 \mathrm{mg} / \mathrm{l}$. (Mahekubpura) to $1000 \mathrm{mg} / \mathrm{l}$ (Unad) (Table 1). Carbonate was either absent or present in negligible amounts. $30 \%$ of the samples were found to be above the BIS (1991) permissible limit i.e. $600 \mathrm{mg} / \mathrm{l}$. This might be be due to various ionic species that contribute to alkalinity like bicarbonate, hydroxide, phosphate, borate and organic acids and these factors are characteristic of the source of water and natural processes taking place at any given time (Sharma, 2004). The high alkalinity imparts water with unpleasant taste, and may be deleterious to human health with high $\mathrm{pH}$, TDS and TH. 
A study of physico-chemical properties of ground

Table 1: Physico-chemical parameters

\begin{tabular}{|c|c|c|c|c|c|c|c|c|c|c|}
\hline \multirow{2}{*}{ Parameter } & \multirow{2}{*}{ Unit } & \multirow{2}{*}{ Max } & \multirow{2}{*}{ Min } & \multirow{2}{*}{ Mean } & \multirow{2}{*}{ Stdev } & \multicolumn{2}{|c|}{ BIS standard } & \multirow[t]{2}{*}{ BDL } & \multirow[t]{2}{*}{$>\mathrm{DL}<\mathrm{PL}$} & \multirow[t]{2}{*}{$<\mathrm{PL}$} \\
\hline & & & & & & Desirable & Permissible & & & \\
\hline $\mathrm{pH}$ & & 7.2 & 8.6 & 7.53 & 0.28 & 6.5 & - & 0 & 59 & 1 \\
\hline Cond & $\mathrm{mS} / \mathrm{cm}$ & 0.43 & 4.98 & 1.28 & 0.73 & - & - & - & - & - \\
\hline TDS & $\mathrm{mg} / \mathrm{l}$ & 85 & 3188 & 814.81 & 476.78 & 500 & 2000 & 8 & 50 & 2 \\
\hline $\mathrm{Na}$ & $\mathrm{mg} / \mathrm{l}$ & 2 & 590 & 102.33 & 125.53 & - & - & - & - & - \\
\hline Alkalinity & $\mathrm{mg} / \mathrm{l}$ & 125 & 1000 & 463.17 & 202.63 & 200 & 600 & 5 & 37 & 18 \\
\hline TH & $\mathrm{mg} / \mathrm{l}$ & 30 & 660 & 131.7 & 110.20 & 300 & 600 & 55 & 4 & 1 \\
\hline $\mathrm{K}$ & $\mathrm{mg} / \mathrm{l}$ & 0 & 57 & 3.75 & 9.16 & - & - & - & - & - \\
\hline $\mathrm{Mg}$ & $\mathrm{mg} / \mathrm{l}$ & 1.22 & 30.39 & 4.88 & 5.56 & 30 & 100 & 59 & 1 & 0 \\
\hline $\mathrm{Ca}$ & $\mathrm{mg} / \mathrm{l}$ & 10 & 240 & 44.70 & 37.66 & 75 & 250 & 53 & 7 & 0 \\
\hline $\mathrm{F}$ & $\mathrm{mg} / \mathrm{l}$ & 0.21 & 5.71 & 1.91 & 1.46 & 1 & 1.5 & 16 & 12 & 32 \\
\hline $\mathrm{Cl}$ & $\mathrm{mg} / \mathrm{l}$ & 50 & 2215 & 277.14 & 326.12 & 250 & 1000 & 38 & 13 & 2 \\
\hline $\mathrm{SO}_{4}$ & $\mathrm{mg} / \mathrm{l}$ & 9 & 100 & 25.3 & 16.05 & 200 & 400 & 60 & 0 & 0 \\
\hline $\mathrm{NO}_{3}$ & $\mathrm{mg} / \mathrm{l}$ & 4 & 40 & 21.02 & 7.61 & 45 & 100 & 60 & 0 & 0 \\
\hline \multicolumn{8}{|l|}{$\mathrm{N}=\mathbf{6 0}$} & & & \\
\hline
\end{tabular}

Electrical Conductivity is a useful tool to evaluate the purity of water (Acharya et al., 2008). In the current research, Electrical conductivity of groundwater samples varied from 0.43(Nanihirvani) to 4.98 (Panchha) $\mu \mathrm{S} / \mathrm{cm}$ (Table 1).Higher EC may be attributed to high salinity and high mineral content at the sampling points. The higher EC of the water samples is the result of ion exchange and solubilisation in the aquifer (Sanchez-Perez and Tremolieres 2003). The Total Dissolved Solids ranged from $85 \mathrm{mg} / \mathrm{l}$. (Arthi) to 3188(Panchha) $\mathrm{mg} / \mathrm{L}$ (Table 1). It was investigated that overall all the samples were within the permissible range given by BIS (1991). As per the TDS classification of Rabinove et al. (1958), 15\% samples were slightly saline category (TDS value range between 1,000 and 3,000 mg/l). According to Davis and DeWiestclasiification 83\% samples are permissible for drinking while $17 \%$ samples are Unsuitable for drinking as far as TDS values are concerned, indicating intense chemical weathering of the minerals bearing rocks. It may be due to stagnant or low flow of ground water and accumulation of dissolved salts (Reddy et al., 2009). Hardness of water is caused by the presence of the multivalent cations and is largely due to calcium and magnesium ions. Hardness varied from 30mg/l (Mahiyal) to $660 \mathrm{mg} / \mathrm{l}$ (Badad). All the groundwater samples except one were in the permissible limit i.e. $600 \mathrm{mg} / \mathrm{l}$ given by BIS (1991)According to Sawyer and McCarty (1978) classification (soft <75, Moderate hard 75-150, Hard 150-300 and Very Hard >300)22\% samples were soft, while $53 \%$ samples were moderate $17 \%$ and $8 \%$ samples were under hard and very hard category. The high concentration of Total hardness in these water samples might be due to dissolution of polyvalent metallic ions from sedimentary rocks, seepage and run off from soil. Our results are in agreement with the study previously done by Dutta, 2010. Sodium is the sixth most abundant element in the Earth's crust and sodium stems from rocks and soils. The sodium $(\mathrm{Na}+)$ content of the groundwater ranged from 2 to $590 \mathrm{mg} / \mathrm{L}$ (Table 1). All were found to be in desirable limit or below it.

Natural waters normally contain low concentration of Potassium. High values of potassium should be looked upon with some suspicion as these may indicate pollution. Neither BIS nor any other organization lay down any limits for potassium content in drinking water (Srivastava, 2007). Potassium of groundwater samples varies from 0mg/l (Limdi) to $57 \mathrm{mg} / \mathrm{l}$ (Chada). Chloride is one of the major inorganic anion of water. The salty 
taste is produced by the chloride concentration is variable and dependent on the chemical composition of water composition. For Chloride, BIS(1991) suggests the limit 250-1000 mg/l. Beyond this limit taste, corrosion and palatability are affected. In the tested water samples concentration of Chloride was found ranging from $50 \mathrm{mg} / \mathrm{l}$ (Fatepura) to $2215 \mathrm{mg} / \mathrm{l}$ (Panccha) with only $4 \%$ samples (i.e. 2 samples) above permissible limit (Table 1) as these villages were found to be in the unsaturated zone. It might be due to accumulation of salt concentration $\left(\mathrm{Cl}^{-}\right)$especially from evaporation or loss of water in this zone. Fluorine is one of the most abundant trace elements in the earth's crust and occurs in natural waters in concentrations depending on the geological setting (Brunt et al. 2004;). High dissolved fluoride concentrations can be found in various geological settings, among them typically crystalline i.e. igneous and metamorphic rocks (Ozsvath, 2009). When drinking water exceeds the guideline value of $1.5 \mathrm{mg} / \mathrm{L}$, there is an increasing risk of dental and skeletal fluorosis, which makes this element of great health concern in many regions (). The Fluoride (F-) content of the ground water ranged from $0.21 \mathrm{mg} / 1$ (Motihirvani) to 5.71 mg/l (Rehmanpura) (Table 1), About 27 of 60 samples was violating permissible limit (1.0-1.5 $\mathrm{mg} / \mathrm{l})$ prescribed by (BIS,1991) (Table 1). This is beacuse alkaline condition of ground water favours the solubility of fluorine- bearing minerals while in acidic medium (acidic $\mathrm{pH}$ ), fluoride is adsorbed in clay. However, in alkaline medium, it is desorbed, and thus alkaline $\mathrm{pH}$ is more favourable for fluoride dissolution activity (). Also the geochemistry of the area is such that it has host rocks of metasedimentary type bearing fluoride containing minerals (Dhiman, 2006). Sulphate content in groundwater generally occurs as soluble salts of calcium, magnesium and sodium. concentration of $\mathrm{SO}_{4}$ of study area fall within the desirable limit of $200 \mathrm{mg} / \mathrm{L}$ prescribed for drinking water prescribed by BIS (1991) and WHO (2004). The Nitrate content of the ground water ranged from $9 \mathrm{mg} / \mathrm{l}$ (Jaspur) to $40 \mathrm{mg} / \mathrm{l}$ (Amarpura) (Table 1).The result indicated that nitrate in all the samples fall below desirable limit given by (BIS 1991). A better understanding of the behaviour and origin of cations and anions in groundwater could be attained by means of correlation analysis among ions. The results of the correlation analysis are presented in Table 2.

Table 2: Correlation analysis of groundwater samples

\begin{tabular}{|c|c|c|c|c|c|c|c|c|c|c|c|c|c|}
\hline & EC & TDS & pH & TA & TH & $\mathrm{Ca}$ & Mg & $\mathrm{Na}$ & $\mathbf{K}$ & $\mathrm{Cl}$ & $\mathbf{F}$ & $\mathrm{SO}_{4}$ & $\mathrm{NO}_{3}$ \\
\hline EC & 1 & .997 & -0.09 & $.372^{(* *)}$ & 0.176 & 0.183 & 0.099 & $.824^{(* *)}$ & -0.018 & $.901^{(* *)}$ & 0.021 & 0.038 & 0.122 \\
\hline TDS & & 1 & -0.107 & $.376^{(* *)}$ & 0.183 & 0.189 & 0.106 & $\left..820^{(* *}\right)$ & -0.02 & $.895^{(* *)}$ & 0.017 & 0.025 & 0.118 \\
\hline $\mathrm{pH}$ & & & 1 & 0.071 & -0.167 & -0.159 & -0.151 & 0.021 & 0.205 & -0.087 & 0.058 & 0.047 & -0.045 \\
\hline $\mathrm{TA}$ & & & & 1 & -0.09 & -0.046 & $-.244^{(*)}$ & $.363^{(* *)}$ & 0.077 & 0.07 & 0.126 & -0.148 & -0.025 \\
\hline $\mathrm{TH}$ & & & & & 1 & $.987^{(* *)}$ & $.757^{(* *)}$ & -0.121 & -0.159 & -0.017 & $-.317^{(* *)}$ & 0.032 & 0.087 \\
\hline $\mathrm{Ca}$ & & & & & & 1 & $.644^{(* *)}$ & -0.118 & -0.161 & -0.011 & $-.329^{(* *)}$ & 0.021 & 0.082 \\
\hline $\mathrm{Mg}$ & & & & & & & 1 & -0.098 & -0.104 & -0.038 & -0.172 & 0.068 & 0.082 \\
\hline $\mathrm{Na}$ & & & & & & & & 1 & 0.054 & $.701^{(*)}$ & 0.202 & 0.125 & -0.056 \\
\hline $\mathrm{K}$ & & & & & & & & & 1 & -0.03 & 0.055 & -0.127 & -0.112 \\
\hline $\mathrm{Cl}$ & & & & & & & & & & 1 & -0.042 & -0.025 & 0.144 \\
\hline$F$ & & & & & & & & & & & 1 & $j^{329^{(* 7+7}}$ & -0.057 \\
\hline $\mathrm{SO}_{4}$ & & & & & & & & & & & & 1 & -0.112 \\
\hline $\mathrm{NO}_{3}$ & & & & & & & & & & & & & 1 \\
\hline
\end{tabular}


A strong positive significant correlation $\mathrm{Na}+-\mathrm{Cl}-$ $(r=0.701)$ indicates dissolution of chloride salts or reconcentration processes by evaporation (Sami, 1992). Also strong positive significant correlation between $\mathrm{Na}+$ and $\mathrm{Cl}-$ with EC and TDS (EC-TDS, r=0.997), (EC-Sodium, r=0.824), (ECChloride, $r=0.901$ ), (TDS-Sodium, $r=0.820$ ), (TDSChloride, $\mathrm{r}=0.895$ ), showed that $\mathrm{NaCl}$ to be major driver of dissolved solids in water. The correlation between fluoride and alkalinity indicates a visible effect of alkalinity over leaching of fluoride. As evident from significant correlations, $\mathrm{F}$ is positely correlated with Sulphate (F-SO4, r=0.329) and inversely related to amount of calcium (F-Ca, $\mathrm{r}=$ 0.329). Also a good correlation existed between $\mathrm{Na}$ and $\mathrm{F}(\mathrm{r}=0.202)$ showing $\mathrm{NaF}$ to be the source for F. To assess the geochemical evaluation in groundwater flow systems, a graphical representation of Piper's diagram (Piper, 1944) is extensively used (Fig. 2). In this, the chemical data of the groundwater samples collected from the study area are plotted in the Piper's diagram.

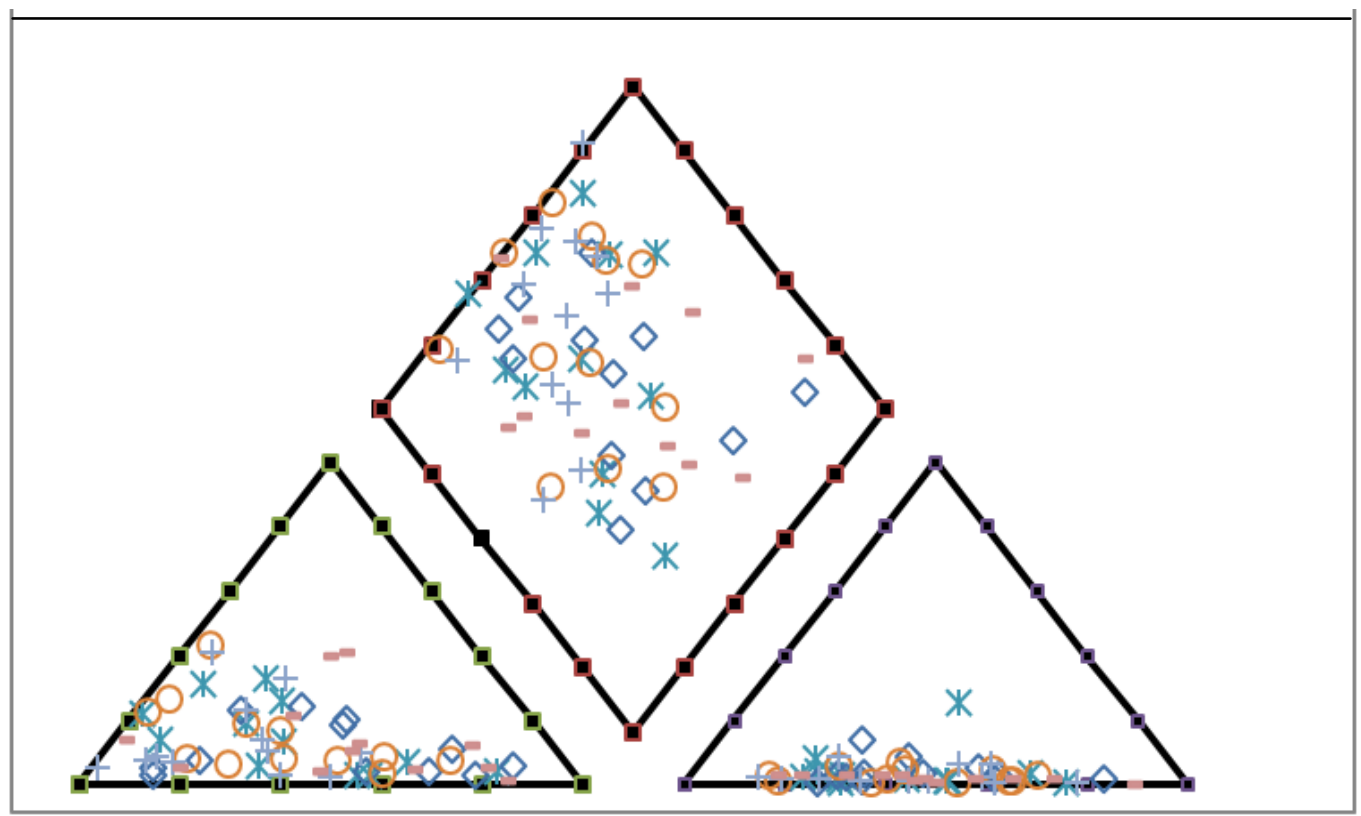

Figure 2: Piper diagram of groundwater samples

Table 3: Sub division of Piper diagram

\begin{tabular}{|l|l|l|}
\hline $\begin{array}{l}\text { Sub division } \\
\text { of diamond }\end{array}$ & Area Subdivisions & $\begin{array}{l}\text { Sample } \\
(\%)\end{array}$ \\
\hline 1 & Alkaline earths exceed alkalies & 73 \\
\hline 2 & Alkalies exceed alkaline earths & 27 \\
\hline 3 & Strong acids exceed weak acids & 50 \\
\hline 4 & Weak acids exceed strong acids & 50 \\
\hline 5 & Carbonate hardness (secondary alkalinity) exceeds 50\% & 37 \\
\hline 6 & Non-carbonate hardness (secondary salinity) exceeds 50\% & 13 \\
\hline 7 & Non-carbonate alkali (primary salinity) exceeds 50\% & 13 \\
\hline
\end{tabular}

The main diamond shape triangle provides the valuable data that the water of kheralutaluka is dominated by alkaline earth metals $\left(\mathrm{Ca}^{2+}\right.$ and $\left.\mathrm{Mg}^{2+}\right)$. As shown in the diagram, $73 \%$ of samples had alkaline earth metal dominating over $27 \%$ samples of alkali metals. Strong acids and weak acids are at equilibrium. Also groundwater samples were found to be dominating in carbonate hardness $\left(\mathrm{Ca}-\mathrm{Mg}-\mathrm{HCO}^{3}\right)$ over carbonate alkali (Na$\mathrm{K}-\mathrm{HCO} 3)$. As weak acids and strong acids are at equilibrium primary salinity is equal to secondary salinity. Classifying by the faces, the major types of 
groundwater samples are of $\mathrm{Ca}-\mathrm{Cl}-\mathrm{HCO} 3, \mathrm{Ca}-\mathrm{CO}_{3}-$ $\mathrm{Cl}$ and $\mathrm{Na}-\mathrm{HCO} 3-\mathrm{Cl}$ rest all other samples have mix faces.

\section{Conclusion}

The physico-chemical analysis of the study revealed that the groundwater in Kheralutaluka is overall moderately hard and alkaline in nature. The High alkalinity and fluoride makes majority of the samples unsuitable for drinking. The major pollutant is fluoride which showed high correlation with alkalinity indicating some mechanism of leaching of fluoride which is affected by $\mathrm{pH}$ and available fluoride in the form of NaF. The hydro-geochemical faces shows that water of kheralutaluka is dominated by alkaline earth metals $\left(\mathrm{Ca}^{2+}\right.$ and $\left.\mathrm{Mg}^{2+}\right)$ and the major types of water are of $\mathrm{Ca}-\mathrm{Cl}-\mathrm{HCO} 3, \mathrm{Ca}-\mathrm{HCO} 3-\mathrm{Cl}$ and $\mathrm{Na}-\mathrm{HCO} 3-\mathrm{Cl}$ rest all other samples have mix faces.

\section{Acknowledgement}

The authors are thankful to Department of Science and Technology for financial support.

\section{References}

A.P.H.A. - A.W.W.A. - W.P.C.F. 1998. Standard methods for the examination of water and wastewater. (20thEd.). Washington, DC

Acharya, G. D., Hathi, M. V., Patel, A. D., \&Parmar, K. C. 2008. Chemical Properties of Groundwater in BhilodaTaluka Region, North Gujarat, India Journal of Chemistry, 5:792-796.

BIS., Specifications for Drinking Water, IS: 10500: 1991, Bureau of Indian Standards, New Delhi, India, 1991.

Brunt, R., Vasak, L. and Griffioen, J. 2004. Fluoride in groundwater: probability of occurrence of excessive concentration on global scale. IGRAC.

Chinoy, N. J., Sheth, F. J. and Multani, A. S. 1994. Sister chromatid exchanges: A study in fluorotic individuals of North Gujarat. Fluoride, 27:215-219

Dutta, J., Nath, M., Chetia, M., and Misra, A. K. 2010. Monitoring of fluoride concentration in ground water of small tea gardens in Sonitpur district, Assam, India: correlation with physico-chemical parameters.Int J Chem Tech Res CODEN USA, 2:1028-1199.

Davis, S.N., DeWiest, R.J. 1966. Hydrogeology. Wiley, NewYork

Dhiman, S. D., and Keshari, A. K. 2006.Hydrogeochemical evaluation of high-fluoride groundwaters: a case study from Mehsana District, Gujarat, India. Hydrological sciences, 51:1149-1162.
Gupta, S. K., Deshpande, R. D., Agarwal, M., and Raval, B. R; 2005. Origin of high fluoride in groundwater in the North Gujarat-Cambay region, India.Hydrogeology, 13: 596-605.

Kori R., Saxena A. and Upadhayay N. 2006. Groundwater quality Assessment of Mandideep Industrial area. National Serminar on Environmental \& Development, Bhopal, 155.

Kumar, N. 2011. Variation of fluoride and correlation with alkalinity in groundwater of shallow and deep aquifers. Int J Environ Sci, 1(5), 884-890.

Ozsvath, D. L. 2009. Fluoride and environmental health: a review. Reviews in Environmental Science and BioTechnology, 8(1), 59-79.

Patel, P. and Bhatt, S. A. 2007. Fluoride: a major polluting component of ground water in North Gujarat region, India. In Proceedings of Taal2007: The 12th World Lake Conference (Vol. 245, p. 249).

Piper AM 1994. A graphical procedure in the geochemical interpretation of water analysis. Am Geophys Union Trans 25:914-928

Rabinove C. J., Long Ford, R. H. and BrookHart, J. W.; 1958. 'Saline water resource of North Dakota, U.S.', Geol. Sur. Water Supply Paper 1428, 72.

Reddy A. G. S., Kumar K. N., Rao S.D. and Rao S.S.; 2009. Assessment of nitrate contamination due to ground water pollution in north eastern part of Anantapur district, A.P. India.Environmental Monitoring and Assessment, 148: 463-476.

Sami, K. 1992. Recharge mechanisms and geochemical processes in a semi-arid sedimentary basin, Eastern Cape, South Africa. Journal of Hydrology, 139(1), 27-48.

Sanchez-Pérez, J. M., \&Trémolières, M. 2003. Change in groundwater chemistry as a consequence of suppression of floods: the case of the Rhine floodplain. Journal of Hydrology, 270: 89-104.

Sawyer GN, McMcartly DL, and Parkin G.F. 2003. Chemistry for environmental engineering and science, 5th ednedn. McGraw Hill, New York, p 752

Sharma, M. R. 2004. Assessment of ground water quality of Hamirpur area in Himachal Pradesh. Pollution Research, 23:131-134.

Srivastava, S. K. 2007. Groundwater quality in parts of Uttarakhand Groundwater 2007. In Proc. National Seminar on Agri. Dev. and Rural Drinking Water (Vol. 2, pp. 305312).Davis, S. N., \& Dewiest, R. J. (1900). Hydrogeology (No. 463pp).

WHO 2004. Guidelines for drinking water quality, 3rd edn. World Health Organization, Geneva 